\title{
An Alternative Non-Traditional Approach to Learning: The Metacognitive-Mapping Approach
}

\author{
Caroline M. Leaf, Brenda Louw and Isabel C. Uys \\ Department of Communication Pathology \\ University of Pretoria
}

\begin{abstract}
The current article is a continuation of a previous article (Leaf, Uys \& Louw 1997) suggesting that alternatives to the current traditional perceptions of learning and therapeutic methods are essential if learning institutions are to enable learners to move successfully into the next millenium. The need for the speech-language therapist to adopt a non-traditional approach to learning and to change from a language instructor to a learning facilitator within a consultative-collaborative role in the unique South African situation is discussed. Research results, specifically relating to how the speech-language therapist can assist teachers in changing to a non-traditional facilitative role, are presented.
\end{abstract}

\section{OPSOMMING}

In hierdie artikel, wat 'n opeenvolging van 'n vorige artikel is, (Leaf, Uys en Louw, 1997) word daar aan die hand gedoen dat alternatiewe tot die tradisionele persepsies van leer en terapeutiese tegnieke noodsaaklik is indien opleidingsinstansies leerders in staat wil stel om die millenium met welslae te betree. Die behoefte vir spraak-taalterapeute om 'n nie-tradisionele benadering tot leer en die leerproses aan te hang, word gemotiveer en die verandering van die spraak-taalterapeut se rol as taalterapeut na 'n fasiliteerder van die leerproses binne ' $n$ samewerkende konsulterende diensleweringsmodel binne die unieke SuidAfrikaanse konteks, word bespreek. Resultate van navorsing oor hoe die spraak-taalterapeut as ondersteuner van onderwysers kan optree in die verandering $n a$ ' $n$ nie-tradisionele fasiliterende rol tydens die leerproses word bespreek.

KEY WORDS: Metacognitive-Mapping, Metacognitive-Mapping Therapy, Metacognitive-Mapping Approach (MMA), braincompatible, geodesic learning, metacognition, learning, collaborative-consultation

\section{INTRODUCTION}

Human potential is judged by the individual's ability to make sense of his world (Cambell, Cambell \& Dickensen, 1992).

There is the need to acknowledge that everyone learns in different ways, and that it is consequently necessary to explore alternative ways of facilitating learning that will allow individuals to realise their natural potential (Leaf, 1997). Current learning systems, that propose to educate and reeducate the "whole" child, tend to favour predominantly linguistic and mathematical intelligences as opposed to a more pluralistic approach (Jensen, 1995). This is a consequence of the prevailing philosophy of current educational systems and therapeutic institutions which indicates that "intelligence" or "potential" is a single general capacity that enables the individual to achieve in all situations. This is an attractive philosophy as it is quantifiable and measurable allowing categorisation of the individual. Research has, however, indicated that this type of approach to developing learning potential, which is based on the I.Q., Piagetian and information processing approaches, is product versus process orientated, and does not develop the whole person to full capacity (Leaf, 1997; Iran-Nejad, 1990; Gardner, 1985; Jensen, 1995; Buzan, 1991). Many educators and philosophers concur that the most important goal of education and therapy is to facilitate thinking. Furthermore, alternatives to the current traditional learning methods are essential if learning institutions are to provide people with effective life skills and enable them to be autonomous learners. This suggestion is based on a body of literature on alternative learning and non-traditional education which stresses the need for fundamental change in the perception of learning in order to cope with the worldwide information explosion (Gardner, 1985; Iran-Nejad, 1990; Knowles, 1990; Gould, 1973; Capra, 1982; Faure, 1972; Jensen, 1995; Novak \& Gowin, 1984; Kline, 1990; de Capdevielle, 1986). An alternative non-traditional approach proposed that focuses on the dynamics of the thought processes and the pluralistic nature of the intelligences of the human mind is the geodesic movement(Leaf, 1997). The details of the geodesic movement are discussed in depth in Leaf (1997) and Leaf Uys \& Louw (1993).

Gould (1973) defines non-traditional learning as an attitude more than a fixed system, with delimited paradigms that can never be defined except tangentially. According to Gould (1973: xvi), "this attitude puts the student first and the institution second, concentrates more on the former's needs than the latter's convenience, encourages diversity of individual opportunity rather than uniform prescription, and de-emphasises time, space and even course requirements in favour of competence and, where applicable, performance. It has concern for the learner of any age and circumstance, for the degree aspirant, as well as the person who finds sufficient 
reward in enriching life through constant, periodic or occasional study."

Alternative approaches to learning consider that learning how to learn and self-directed inquiry are essential life skills which enable systems as well as the people within the systems to bring about their own transformation in response to changing situations and requirements. Faure (1972) indicates that education and learning must be conceived of as an existential continuum as long as life, and not limited in time to "school age", or confined in space to "school buildings" and institutions. Traditional education makes the communication and accrual of knowledge facts the primary objective. Non-traditional education considers the amount of knowledge as being secondary. The primary objective of non-traditional education is to develop the power of the mind and to aid the learner, both mentally and morally, in using his powers properly for the pursuit and application of knowledge. Therefore, an alternative nontraditional geodesic approach to learning emphasises the need to teach how to learn and not what to learn. Figure 1 provides a comparison of holistic and traditional approaches to learning.

Furthermore, the literature indicates that alternative nontraditional approaches to learning require an attitude change in order to deal with the flexibility of society and all of its institutions, which are in a continuing state of transformation (Leaf, 1997; Iran-Nejad, 1990; Gardner, 1985; Jensen, 1995; Knowles, 1990; Okebukola, 1992). Research by Leaf (1997) lends support to this contention in that attitude was found to be a fundamental criterion for effecting a change in perception towards learning. The results of the research (Leaf, 1997) demonstrated that attitude produces what is known as the "maintenance effect" - the inability to move beyond a perceptual paradigm. Botkin, Elmandjra and Malitza (1979 : 49 ) indicate that "serious doubt must be raised as to whether conventional human learning processes are still adequate today". They state that traditional learning methods foster a pattern of "maintenance learning", where fixed methods, outlooks and rules - paradigms - are used to deal with known situations, which increases an individual's ability to cope with what is known, but ignores what is not known. This can be compared to the Khunian effect where the unexpected is ignored and changed to fit into an existing paradigm (Khun, 1979, in Barker, 1986). Maintenance learning therefore maintains an existing system or way of life. This "maintenance" or "Khunian" effect was observed repeatedly in the research done by Leaf (1997) where the MMA methods were adapted and changed by the teachers and therapists to fit into the traditional approach, as opposed to the geodesic system being adopted as a new entirely global system different from the traditional system. Maintenance learning plays an indispensable role in the functioning of societies, but, for longterm survival, "learning that can bring change, renewal, restructuring, and problem reformulation" is essential. Hence, learning institutions need to develop innovative as well as maintenance learning, and not maintenance learning alone. The latter will create the paradigm effect where "past success can block future vision" (Barker, 1987). The best of the traditional needs to be adapted into the more holistic braincompatible geodesic approach and not vice-versa.

It is postulated that the "maintenance learning" and "Khunian effect" phenomena are the result of resistance to change, which is an accepted facet of human nature (Barker, 1987). Okebukola (1992) researched the attitudes of teachers, who are the key agents in the diffusion process of an educa- tional innovation, towards the use of concept-mapping and “vee-diagramming" (Novak \& Gowin, 1984). The underlying philosophy of these techniques is of a geodesic nature which requires a change in teachers to a new alternative approach. $\mathrm{He}$ found that, after a five-day training course which included practical application in the classroom, there was a favourable attitude in the teachers towards the use of the geodesic concepts - particularly concept-mapping which has similarities to Metacognitive-Mapping - in cultural subjects, but not in Maths. He also found that although the teachers' skill levels improved, they experienced difficulty in teaching the methods to the pupils. The research by Leaf (1997) confirms Okebukola's (1992) findings that attitudes and skills can be changed, and that teachers perceive geodesic methods as easier to apply with cultural subjects than with Maths. However, it is believed that the "favourable" attitude of Okebukola's (1992) study was the equivalent of a change in only the cognitive component of attitude and the knowledge levels of the current research, and not indicative of a permanent change in the teachers' philosophy. Furthermore, although the underlying philosophy of concept-mapping and vee-diagrams is geodesic, the methods themselves have remnants of traditional linear methodology in them.

The paradigm shift that is occurring in the perception of learning is paralleled in the field of Speech-Language Therapy and Audiology, and has resulted in a paradigm shift in the professional self-concept of and role played by the speechlanguage therapist (Leaf, 1997; Leaf, et al., 1993). This paradigm shift has emerged in response to the increasing awareness of the inefficiency of traditional approaches in meeting the needs of clients, with alternative service delivery models proposed to provide a more accountable service to clients. These issues are discussed in detail in Leaf, 1997 and Leaf et al., 1993. Research by Leaf (1997) provides evidence of this paradigm shift as the speech-language therapists demonstrated a significant positive change in their knowledge, attitude and skills regarding geodesic concepts. Furthermore, this change was significantly larger than the changes demonstrated by the teacher's group. This indicates that the speech-language therapists of this study (Leaf, 1997) responded to the need to change in order to provide a more accountable service to pupils with learning disabilities. One of the communication needs stressed in the alternative service delivery literature is the need to integrate communication skills with academic material (Leaf, 1997; Leaf et al., 1993; Paul-Brown, 1992). Speech-language therapists need to broaden their role to be able to promote overall school success, and in this way, provide a more accountable service to clients. Speech-language therapists need to become more involved in facilitating the language and communication skills needed in the learning process in the classroom.

This change therefore implies an evolution. According to Johnson (1987: 225), "the evolution from 'speech-language therapist' to 'communication instructor' has been the result of adopting an educational model versus a medical model, through integrating communication instruction into the students' natural learning environment, and through collaborating with other educators". This entails the use of classroom and curriculum based service delivery models where the basis for the content of treatment would be the concepts and vocabulary from the academic curriculum. This was one of the reasons for the development of the MMA training programme (Leaf, 1997) as a curriculum-based service delivery model to be utilised by both the teacher and the speechlanguage therapist within a facilitatory framework. It was 


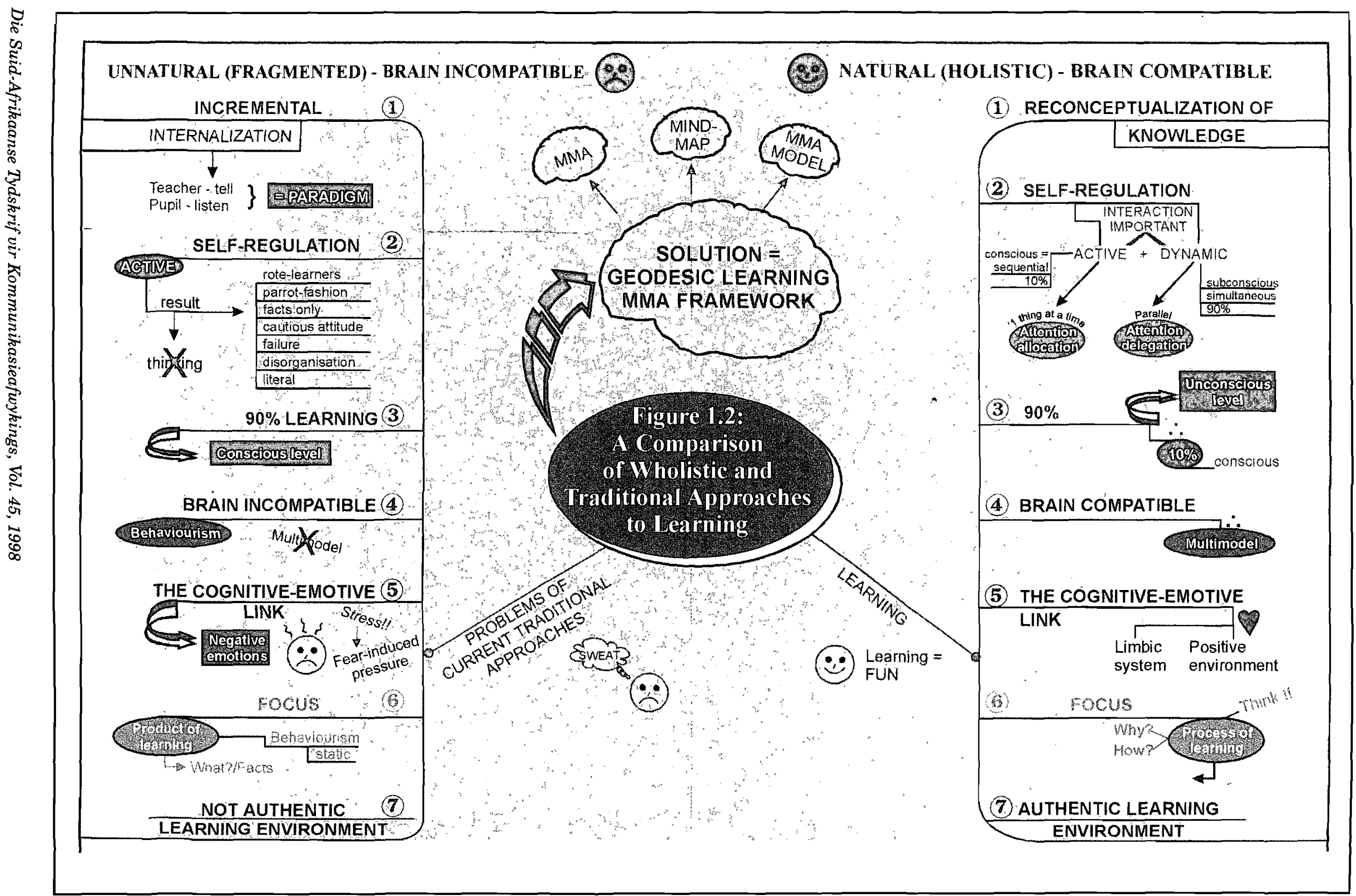


envisaged that the speech-language therapist would utilise the MMA methods in therapy, and in addition to this, would collaborate with the teachers regarding the pupils, and finally, would serve in a consulting role, assisting and facilitating the utilisation by the teachers of the MMA methods in the classroom.

The study by Leaf (1997) revealed that after training in the MMAgeodesic philosophy, the speech-language therapists used the MMA methods in 1:1 therapy, that more group therapy was initiated, and that there was more collaboration with the teachers. However, none of the three speech-language therapists, who acted as respondents, reported actually going into the classroom and working with the teacher and children in a consultative role. It appeared that three of the 12 remedial teachers, rather than the speech-language therapists, played more of a consultative role, and were the driving force regarding Metacognitive-Mapping in the classroom. These results need to be interpreted with caution as the sample size of speech-language therapists was extremely limited in the study (Leaf, 1997). However, certain theoretical implications can be deduced. It appears that, despite the awareness of the need for change, the speech-language therapists in the current study were not comfortable with the classroom environment and did not feel competent to deal with the curricular and language demands, nor with the larger groups. The remedial teachers, on the other hand, had a better understanding of the academic environment due to their pedagogical background, and for this reason may have been more comfortable. Therefore, it appears that speech-language therapists need to be familiarised with the academic environment and the process of teaching in order to feel more comfortable in the classroom. This has implications for training of speechlanguage therapists on both under and post graduate levels.

These findings support research done by Gerber (1987) and Simon (1987), who indicate that some form of continuing education is essential if collaboration and consultation between teachers and therapists is to be successful. It would appear that the appropriate way forward would be to provide teachers with training about the nature of language and communication, and the dynamic nature of the learning process; likewise, speech-language therapists need training in the nature of classroom curriculum and its associated language demands. According to Tattershall (1987: 181), speech-language therapists need to "learn how a classroom works before its too late". The traditional training of speech-language therapists needs to include consultation skills as required competencies before it is too late. Furthermore, the results of the study by Leaf (1997) indicate that teachers and therapists need training relating to the geodesic nature of learning, specifically in relation to neuropsychological and metacognitive concepts.

The importance of the speech-language therapist as a collaborative consultant utilising alternative geodesic approaches is highlighted by Simon (1987), who postulates that well-meaning traditional speech-language therapists have actually ended up creating "educational casualties" as a consequence of segregating and labelling students, leading them to becoming addicted to $1: 1$ attention. This has contributed to the development of passive attitudes towards learning in so-called "learning disabled" students, who fall into patterns of "learned helplessness" due to their believing the label "disabled" (Altwerger \& Bird, in Damico, 1987). The speech-language therapist can play an essential role in the creation of active, responsible and innovative learners specifically with those clients with learning disabilities who have long histories of attending 1:1 therapies.
"Education in transition" is one of the "buzz" phrases in South Africa and massive educational restructuring, reform and research in terms of "a new political dispensation is required so that realistic choices can be made" (Lazar, 1994:8). Within the unique South African situation, a changing school going population has become the most important factor in providing effective service. The South African classroom is becoming more complex and heterogenous along racial, linguistic and cultural lines making the job of teaching increasingly more difficult. Speech-language therapists are now, more than ever faced with the need to change to a collaborative-consultative role. Within the proposed outcomes based education (OBE), the role of the speech-language therapist will become increasingly important in the facilitation and implementation of the system for the reasons discussed above. However, due to monetory constraints, the government is reducing instead of increasing the number of posts available to speech-language therapists. Consequently there will be a shift in responsibility from the state-employed speechlanguage therapist to the privately employed speech-language therapist. In order to prepare for this role, the speech-language therapist in South Africa needs to be aware and understand not only the concepts of the OBE, but also the mindset of the teachers who have been operating within traditional systems as well as the constraints of the South African situation for many years. It is believed that this will ease the speechlanguage therapist into a consultative-collaborative role more easily, as well as enabling them to be more effective within this role. Research done by Leaf (1997) has specifically examined the attitude, knowledge and skills of a group of South African teachers and therapists towards traditional and non-traditional learning concepts before and after exposing them to an alternative non-traditional geodesic system. The results of the research (Leaf, 1997) were both encouraging and sobering. In the ensuing section, the results of the study, as well the implications of these results for the speechlanguage therapist as a collaborative-consultant will be discussed.

\section{THE EXAMINATION OF THE KNOWLEDGE, ATTI- TUDE AND SKIILS OF TEACHERS TOWARDS NON- TRADITIONAL GEODESIC CONCEPTS BEFORE AND AFTER EXPOSURE TO A NON-TRADITIONAL GEODESIC SYSTEM}

The research by (Leaf, 1997) identified the reasons why change in traditional perceptions of learning is needed by tracing the philosophies of contemporary traditional methods and their effect on the perception of learning, and it proposed an alternative geodesic approach, the Metacognitive-Mapping approach (MMA). The research employed an adapted ABA design which was essentially a pre-test post-test control group design examining the cause and effect of an extraneous variable (the MMA training programme). The research comprised two experiments: one, the training of the teachers and therapists in the MMA programme; and two, the application of the MMA programme in education and theraby with the learners by the teachers and therapists. The subjects of experiment one comprised 26 teachers (Grade 1 to Grade 7), 3 .speech-language therapists, 12 remedial teachers, 3 occupational therapists and one psychologist from the three selected remedial schools. The subjects of experiment two were the learners of the three selected remedial schools who had identified language and learning disabilities. The basic procedure of the research is identified in Figure 2. 
Inherent in the MMA model is the implication that traditional methods do not facilitate effective wholistic thinking and as a result, do not produce innovative life-long learners. The broad topic of teaching and providing therapy to learners consists of the distinctive domains of curriculum, instruction, management and assessment (Palmer et al., 1989). The MMA procedure lies within the domain of instruction and may be applied to any curriculum or therapy context at any age level. The MMA philosophy also provides an approach to curriculum, management and assessment. Therefore, extrapolated from the MMA model and its assumptions, is a practical framework, the MMA, that when implemented within learning environments, will foster geodesic thinking which is in natural compliance with the functioning of the brain and therefore to be preferred.

\section{THE CHANGE IN KNOWLEDGE}

In the study by Leaf (1997), the knowledge, attitude and skills of the teachers and therapists was examined in relation to the concepts of neuropsychology and metacognition, (see definitions) as these are the fundamental concepts underlying the geodesic approach of the MMA. In this section, knowledge relating to metacognition and neuropsychology will be discussed. The results of the study (Leaf, 1997) showed that the teachers and therapists had more knowledge about the importance of neuropsychological concepts and learning than metacognitive concepts, and that knowledge about neuropsychology in the pre-training phase was high (see Table 1).

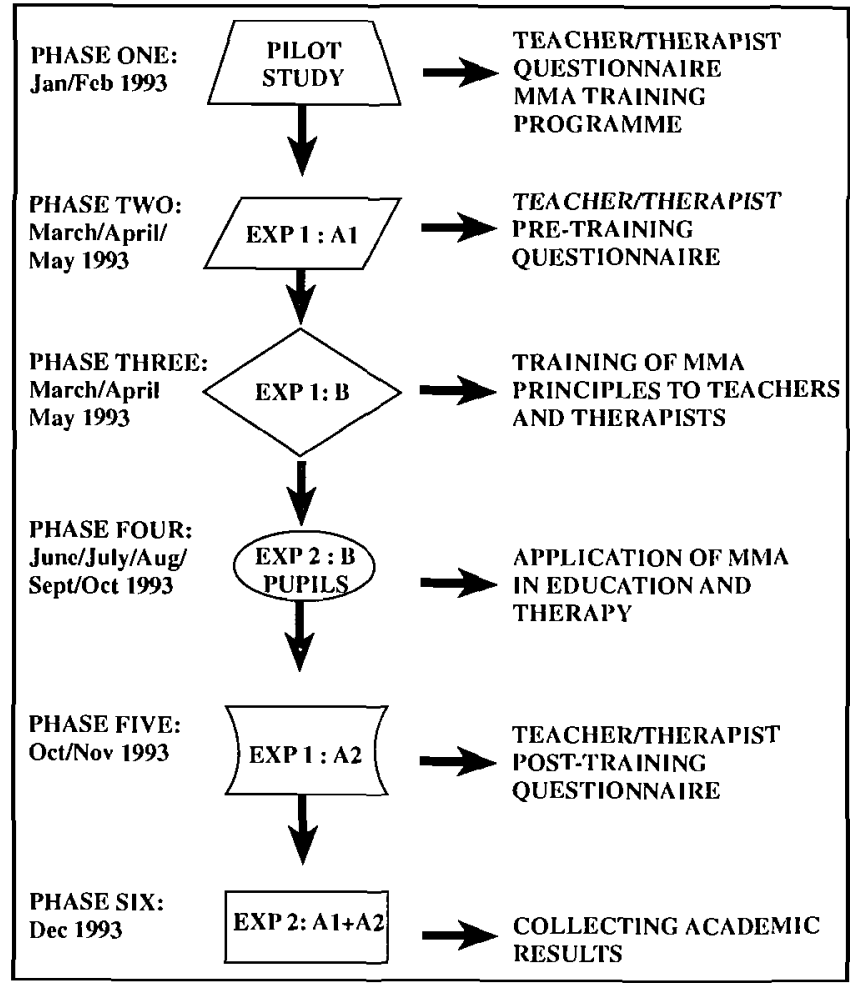

FIGURE 2: Schematic layout of the order of the general procedure of the experiment

TABLE 1 : The change in knowledge, attitude and skills regarding the geodesic principles of the MMA

\begin{tabular}{|c|c|c|c|c|c|}
\hline \multicolumn{6}{|c|}{$\begin{array}{l}\text { Results of the Wilcoxon Signed Rank Test: Comparing the } 6 \text { Pre vs Post Learning Categories of the } \\
\text { Questionnaire }(N=45)\end{array}$} \\
\hline \multirow{2}{*}{ CATEGORY } & \multicolumn{2}{|c|}{ PRE } & \multicolumn{2}{|c|}{ POST } & \multirow{2}{*}{$\frac{\text { P-VALUE }}{(0.05}$} \\
\hline & & $\mathbf{S}$ & & $\mathbf{S}$ & \\
\hline $\begin{array}{c}\text { KNOWLEDGE } \\
\text { NEUROPSYCHOLOGY } \\
(\mathrm{KN})\end{array}$ & 0.61 & 0.11 & 0.63 & 0.06 & 0.2821 \\
\hline $\begin{array}{c}\text { KNOWLEDGE } \\
\text { METACOGNITION } \\
(\mathrm{KM})\end{array}$ & 0.45 & 0.10 & 0.54 & 0.10 & $0.0001 *$ \\
\hline $\begin{array}{c}\text { ATTITUDE } \\
\text { NEUROPSYCHOLOGY } \\
\text { (AN) }\end{array}$ & 0.73 & 0.12 & 0.78 & 0.09 & $0.0067:$ \\
\hline $\begin{array}{c}\text { ATTITUDE } \\
\text { METACOGNITION } \\
(\mathbf{A M})\end{array}$ & 0.55 & 0.10 & 0.53 & 0.11 & 0.2363 \\
\hline $\begin{array}{c}\text { SKILL } \\
\text { NEUROPSYCHOLOGY } \\
\text { (SN) }\end{array}$ & 0.30 & 0.17 & 0.39 & 0.10 & $0.0003 *$ \\
\hline $\begin{array}{l}\text { SKILL } \\
\text { METACOGNITION } \\
\text { (SM) }\end{array}$ & 0.48 & 0.10 & 0.55 & 0.10 & $0.0001 *$ \\
\hline $\begin{array}{l}\text { TOTAL SCORES } \\
\text { (All six categories above) }\end{array}$ & 0.51 & 0.077 & 0.57 & 0.07 & $0.0001 *$ \\
\hline
\end{tabular}

$\mathrm{S}=$ Standard deviation 
This result is predictable due to the amount of information in the media and books on the left and right hemispheres of the brain, and increased awareness that "whole-brain" learning requires alternative approaches. The question can therefore be raised: if there is such widespread knowledge of how the brain works, why is this knowledge not being applied in learning environments? This is possibly because traditional behaviouristic approaches to learning do not consider the "how" of learning or a knowledge of the functioning of the brain to be a contributing factor to the improving and/or release of potential (Buzan, 1991; Jensen, 1995; Novak \& Gowin, 1984). Iran-Nejad (1990) argues that traditional approaches undermine the creative and multimodal nature of learning, limiting its domain to the rote learning of facts and definitions. This is because traditional behaviouristic approaches to learning generally assume learning to be the internalisation of external knowledge controlled by a single central self-regulatory centre (Leaf, 1997; Iran-Nejad, 1990).

According to surveys on the relationship between brain function and learning skills (Buzan, 1991; Jensen, 1995), little or no information is given to students about the function of the human brain and learning during the informative academic years. It appears then that traditional philosophies regarding learning principles persist even though the teachers and therapists "know better". For example, the high percentage of teachers and therapists that considered repeated reading through ones work to be "learning" is evidence that traditional behaviouristic philosophies still persist in current educational institutions, as well as being evidence of how entrenched these beliefs are.

Furthermore, all the means in the Knowledge Neuro- psychology category, (see Table 2 and Figure 3) although changed, were still low in the post-training phase, which leads to speculation regarding the consistency of the changes that occurred. It appears that the teachers and therapists were not sufficiently convinced that they needed to change their entire approach, and continuing to use predominantly traditional methods, adopting only isolated components of the geodesic approach in a disjointed fashion. The other erroneous paradigms or beliefs relating to the issue of neuropsychological knowledge that continued to persist, and that need to be taken into consideration when working within a consultative role were as follows:

- The human brain is not very creative (as opposed to the human brain being exceptionally creative given the correct facilitation).

- The left hemisphere is dominant for learning (as opposed to a synergistic processing between the hemispheres being an essential requisite of effective learning).

- Too much stimulation in the learning environment will decrease learning (as opposed to the individual learning most effectively through multimodal multistimulation).

- Visualisation is a fun activity but plays no real role in the learning environment (as opposed to visualisation being the way information is stored in the brain, as well as being the activator of learning).

- Intelligence is one-dimensional and is measurable by I.Q. testing (as opposed to intelligence being multidimensional, and thus I.Q. testing giving an indication of mathematical and linguistic intelligence only).

- The teacher or therapist is responsible for what students

TABLE 2 : The change in Neuropsychological Knowledge (KN)

\begin{tabular}{|c|c|c|c|c|c|c|c|c|c|c|}
\hline QUESTION & \multicolumn{5}{|c|}{ PRE-TRAINING VALUES } & \multicolumn{5}{|c|}{ POST-TRAINING VALUES } \\
\hline & \multicolumn{2}{|c|}{ YES } & UNSURE & \multicolumn{2}{|c|}{ NO } & \multicolumn{2}{|l|}{ YES } & UNSURE & \multicolumn{2}{|r|}{ No } \\
\hline $\mathbf{B 1}$ & \multicolumn{2}{|l|}{$93.3 \%$} & $0 \%$ & \multicolumn{2}{|c|}{$6.7 \%$} & \multicolumn{2}{|l|}{$88.9 \%$} & \multicolumn{2}{|l|}{$4.4 \%$} & $6.7 \%$ \\
\hline $\mathbf{B 2}$ & \multicolumn{2}{|l|}{$84.4 \%$} & $8.9 \%$ & \multicolumn{2}{|c|}{$6.7 \%$} & \multicolumn{2}{|l|}{$88.9 \%$} & \multicolumn{2}{|l|}{$4.4 \%$} & $6.7 \%$ \\
\hline B3 & \multicolumn{2}{|l|}{$91.1 \%$} & $6.7 \%$ & \multicolumn{2}{|c|}{$2.2 \%$} & \multicolumn{2}{|l|}{$88.9 \%$} & \multicolumn{2}{|l|}{$11.1 \%$} & $0 \%$ \\
\hline B4 & \multicolumn{2}{|l|}{$4.4 \%$} & $8.9 \%$ & \multicolumn{2}{|c|}{$86.7 \%$} & \multicolumn{2}{|l|}{$0 \%$} & \multicolumn{2}{|l|}{$6.7 \%$} & $93.3 \%$ \\
\hline $\mathbf{B 7}$ & \multicolumn{2}{|l|}{$26.7 \%$} & $11.1 \%$ & \multicolumn{2}{|c|}{$62.2 \%$} & \multicolumn{2}{|l|}{$13.3 \%$} & \multicolumn{2}{|l|}{$6.7 \%$} & $80 \%$ \\
\hline $\mathbf{B 9}$ & \multicolumn{2}{|l|}{$88.9 \%$} & $2.2 \%$ & & $9 \%$ & $88.9 \%$ & & $8.9 \%$ & & $2.2 \%$ \\
\hline B11 & $75.6 \%$ & & $22.2 \%$ & & $2 \%$ & $86.7 \%$ & & $8.9 \%$ & & $4.4 \%$ \\
\hline B13 & $97.8 \%$ & & $0 \%$ & & $2 \%$ & $95.6 \%$ & & $4.4 \%$ & & $0 \%$ \\
\hline B18 & $86.7 \%$ & & $8.9 \%$ & & $4 \%$ & $93.3 \%$ & & $4.4 \%$ & & $2.2 \% \quad$ । \\
\hline QUESTION & & PE-TR & AINING V & LUES & & & OST-T & RAINING & ALUES & \\
\hline & EXPERT & & SOME & & TLE & EXPER & & SOME & & GITTLE \\
\hline C1 & $8.9 \%$ & & $57.8 \%$ & & $3 \%$ & $2.2 \%$ & & $88.9 \%$ & & $8.9 \%$ \\
\hline C3 & $8.7 \%$ & & $64.4 \%$ & & $7 \%$ & $4.4 \%$ & & $86.7 \%$ & & $8.9 \%$ \\
\hline $\mathrm{C8}$ & $4.4 \%$ & & $62.2 \%$ & & $9 \%$ & $2.2 \%$ & & $80 \%$ & & $17.8 \%$ \\
\hline C9 & $6.7 \%$ & & $71.1 \%$ & & $2 \%$ & $6.7 \%$ & & $86.7 \%$ & & $6.7 \%$ \\
\hline QUESTION & & PRE-T & RAINING & ALUE & & & OST-T & RAINING & ALUES & \\
\hline & & & $\overline{\text { ELEMEN }}$ & & & & & ELEMEN & & \\
\hline & 1 & 2 & 3 & 4 & $\mathbf{5}$ & 1 & 2 & 3 & 4 & 5 \\
\hline$\overline{\mathbf{E 2}}$ & $64.4 \%$ & $68.9 \%$ & $26.7 \%$ & $20 \%$ & $4.1 \%$ & $80 \%$ & $80 \%$ & $28.9 \%$ & $22.2 \%$ & $13.3 \%$ \\
\hline E3 & $6.7 \%$ & $77.8 \%$ & $6.7 \%$ & $4.4 \%$ & $0 \%$ & $6.7 \%$ & $91.1 \%$ & $15.6 \%$ & $2.2 \%$ & \\
\hline
\end{tabular}


should learn, and how, when and if they have learned (as opposed to the teacher or therapist being a process manager guiding self-directed content resourcefulness).

The significant improvement noted in the knowledge about metacognition category indicates that there was a change in the status of the teachers' and therapists' knowledge of metacognitive concepts (see Table three and Figure 4). However, the means for this category were even lower than for the knowledge about neuropsychology category, which indicates that metacognition is a problem area. Metacognition seems to be a difficult concept for teachers and therapists to grasp. This is not surprising considering the confusion in the literature regarding this topic. According to Brown (1978), the definition of metacognition needs considerable clarification. The low means in the Knowledge Metacognition category provide further support to the idea of entrenched traditional learning paradigms that were difficult to change. Erroneous ideas on metacognition still persisting in the posttraining phase were:

- Reading fast reduces comprehension of the material being read (as opposed to increasing the comprehension due to the brain taking in whole units of meaning).

- Using a pacer whilst reading reduces comprehension (as opposed to increasing comprehension due to the pacerifacilitating a more effective eye movement).
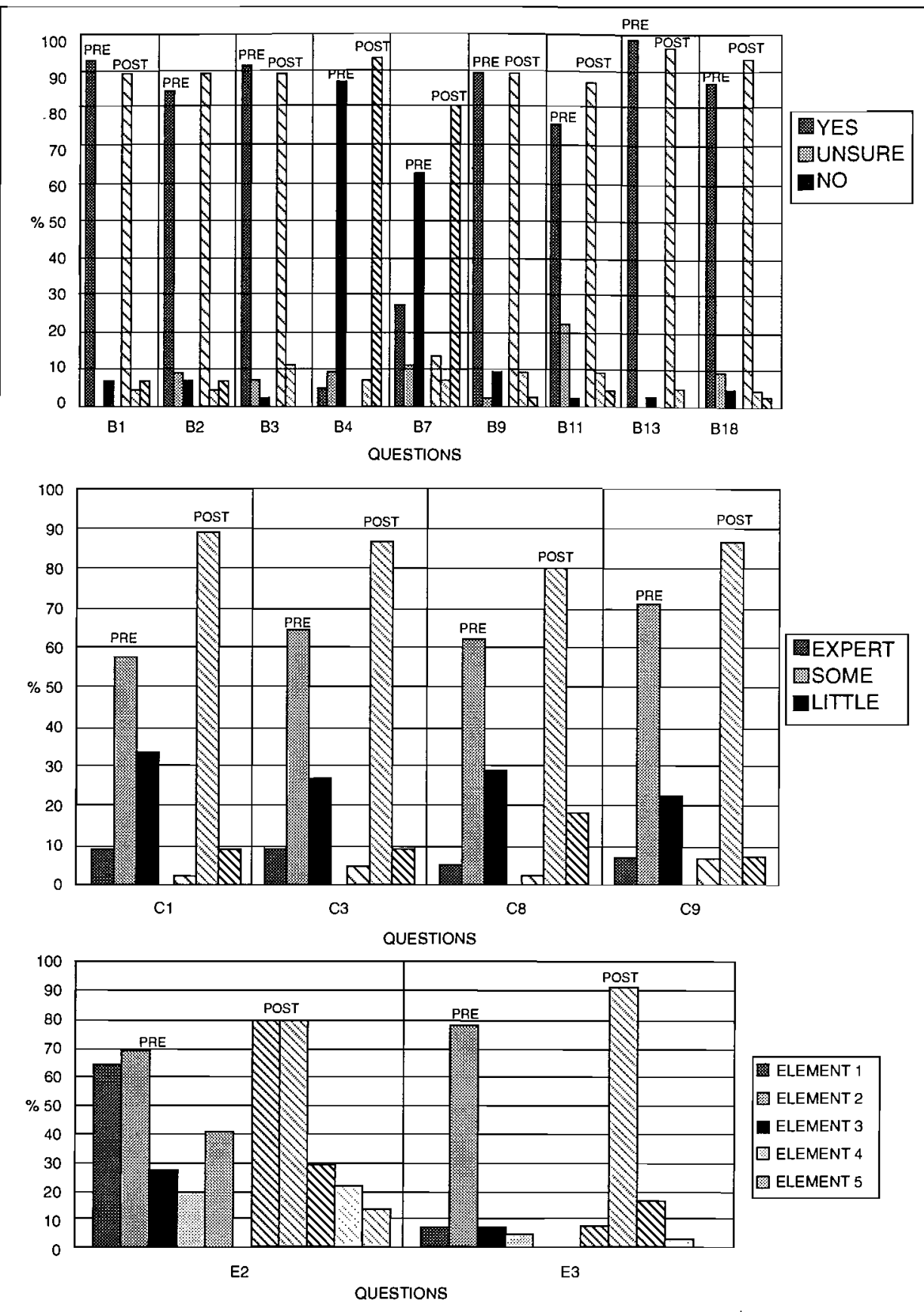

- Linear monochromatic notemaking techniques facilitate learning (as opposed to inhibiting learning due to only a minimal amount of leftbrain processing being activated).

- Key words and key concepts are the same (as opposed to being different, the concept being more important as the brain processes and stores units of meaning, which are concepts).

- Factual recall is more important than creativity in the learning situation (as opposed to creativity being the result of synergistic processing between the hemispheres and therefore vitally important to the learning process).

- Learning is the internalisation of external facts, or the storage of facts for later reproduction (as opposed to the view that a change will occur as a result of the creative reconceptualisation of knowledge).

- The non-conscious plays only a very basic perceptual role in learning (as opposed to controlling approximately

$90 \%$ of the learning process).

- Accelerated learning does not exist (as opposed to accelerated learning being the norm, and traditional philosophies retarding what is normal).

- A good teacher can get children to rote-learn and produce a good end-product, that is high academic results (as opposed to a teacher having the function of process designer and manager, involving pupils in planning, linking to learning resources, and encouraging initiative).

- Thinking skills should be taught as a subject (as opposed to being an all encompassing structure guiding every interaction with pupils).

- The highest level of thought is cognition (as opposed to cognition being the result of conscious thought, which is in turn guided by metacognition, the highest level of thought). 
In summary, the MMA training made a difference to the knowledge about neuropsychology and metacognition of the teachers and therapists but the means were lower than predicted. This leads to the speculation that the change experienced by the teachers and therapists was not large enough to overcome the entrenched traditional paradigms regarding learning principles. Thus, the teachers and therapists will probably only use the geodesic methods partially and inconsistently and eventually become demotivated and revert to predominantly traditional behaviours in teaching and therapy. The question arises: how should the MMA training be adapted in order to effect a change in paradigms in the long term? Firstly, one needs to bear in mind the erroneous ideas on neuropsychological and metacognitive concepts, focusing on these when working with the teachers. Secondly, the attitude of the teachers towards non-traditional concepts needs significant attention. It is posited that the attitude of therapists and teachers plays an important role in effecting change. Researchers have long recognised the practical importance of attitude change, as this process has been the subject of careful study for several decades in organisational behaviour and adult education (Byron, 1986; Knowles, 1990). In the next section, the attitude to neuropsychology and metacognition will be explored in order to investigate the possibility of a correlation between the results of these two pairs of categories.

\section{THE CHANGE IN ATTITUDE}

The results in the Attitude Neuropsychology (see Table 4 and Figure 5) category showed a significant positive change towards neuropsychological concepts in the posttraining phase, whereas the Attitude Metacognition (see

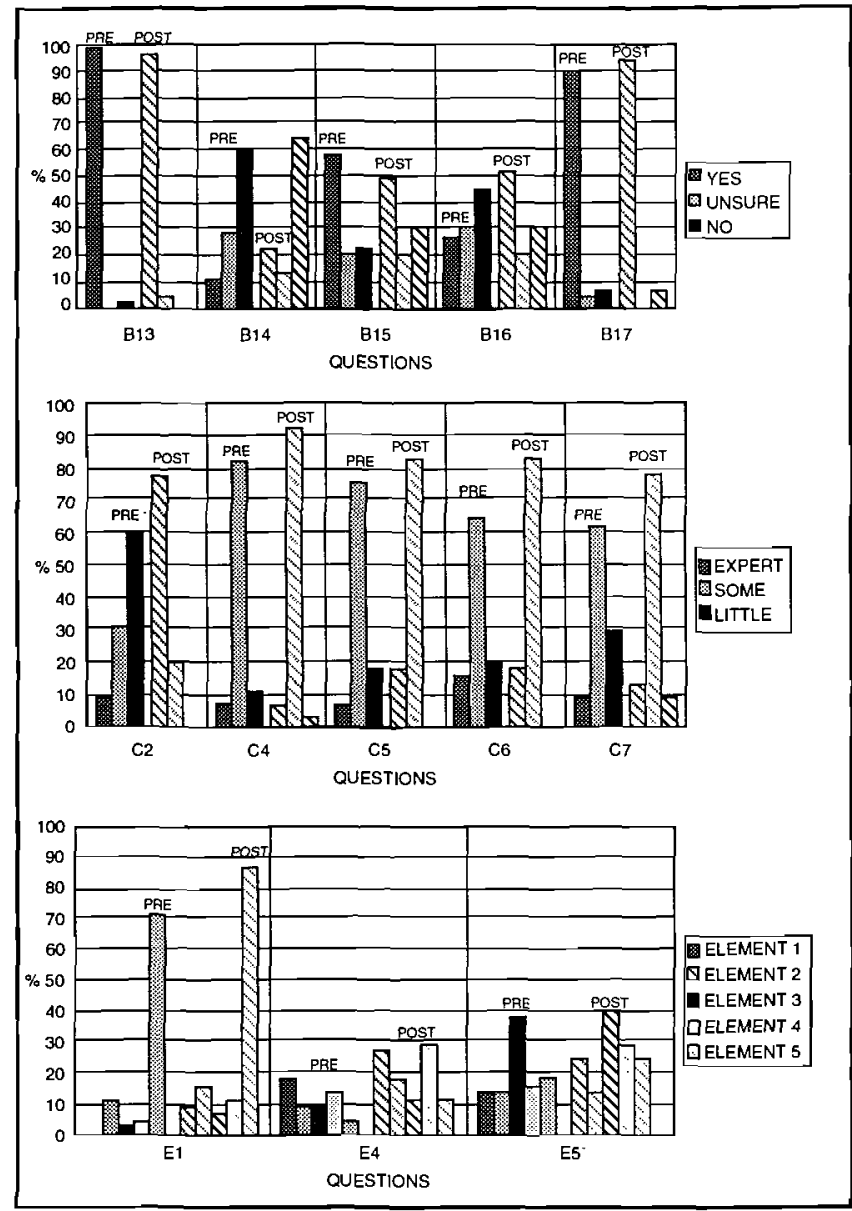

FIGURE 4. The Change in Metacognitive Knowledge (KM)

TABLE 3: The change in Metacognitive Knowledge (KM)

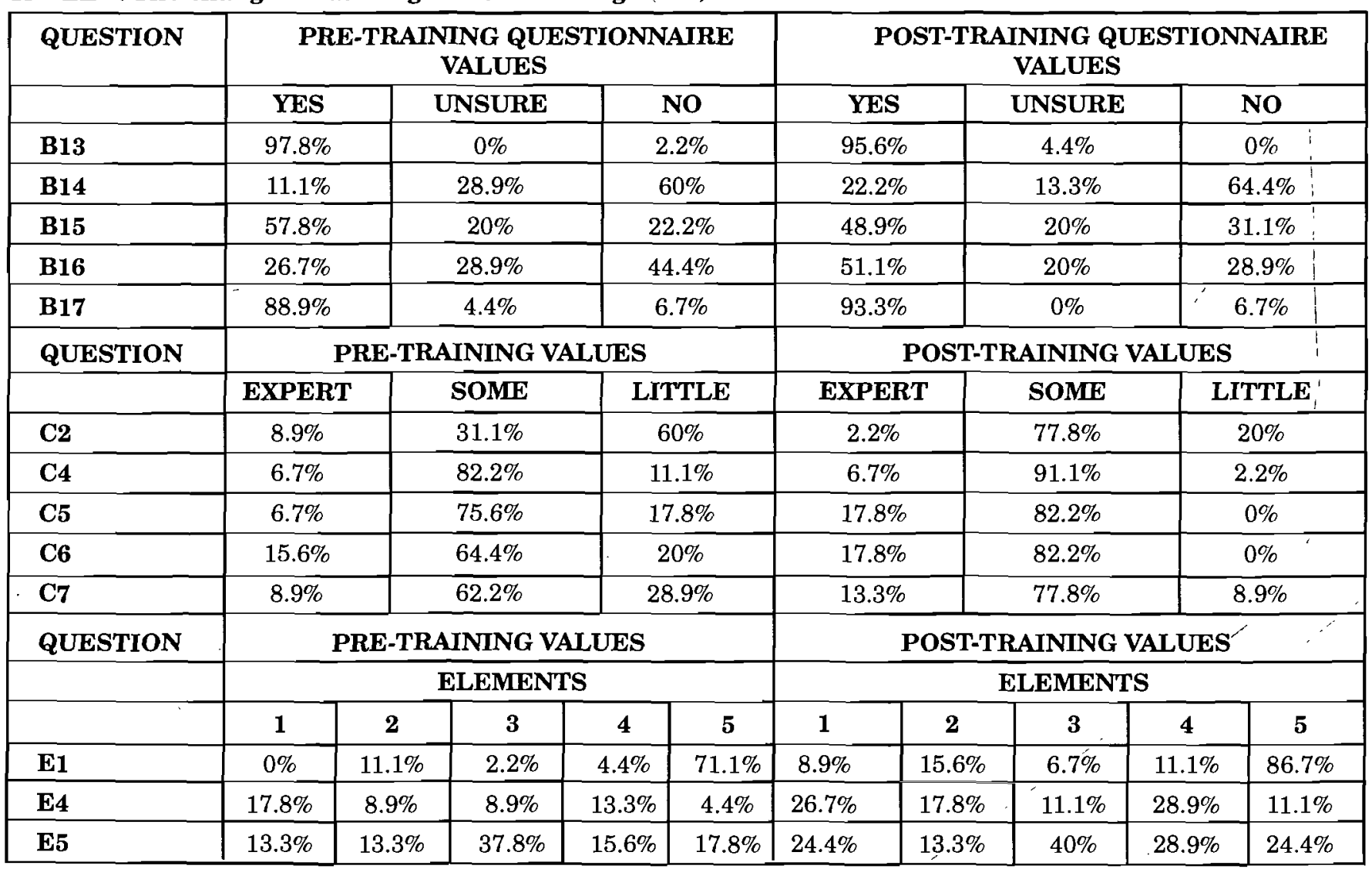


TABLE 4: The change in attitude towards Neuropsychological Concepts (AN)

\begin{tabular}{|c|c|c|c|c|c|c|c|c|c|c|c|c|}
\hline \multirow[t]{2}{*}{ QUESTION } & \multicolumn{6}{|c|}{ PRE-TRAINING VALUE } & \multicolumn{6}{|c|}{ POST-TRAINING VALUE } \\
\hline & \multicolumn{2}{|l|}{ YES } & \multicolumn{3}{|c|}{ UNSURE } & NO & \multicolumn{2}{|l|}{ YES } & \multicolumn{3}{|c|}{ UNSURE } & NO \\
\hline $\mathbf{B 2}$ & \multicolumn{2}{|l|}{$84.4 \%$} & \multicolumn{3}{|c|}{$8.9 \%$} & $6.7 \%$ & \multicolumn{2}{|l|}{$88.9 \%$} & \multicolumn{3}{|c|}{$4.4 \%$} & $6.7 \%$ \\
\hline B3 & \multicolumn{2}{|l|}{$91.1 \%$} & \multicolumn{3}{|c|}{$6.7 \%$} & $2.2 \%$ & \multicolumn{2}{|l|}{$88.9 \%$} & \multicolumn{3}{|c|}{$11.1 \%$} & $0 \%$ \\
\hline B10 & \multicolumn{2}{|l|}{$62.2 \%$} & \multicolumn{3}{|c|}{$8.9 \%$} & $28.9 \%$ & \multicolumn{2}{|l|}{$77.8 \%$} & \multicolumn{3}{|c|}{$4.4 \%$} & $17.8 \%$ \\
\hline B11 & \multicolumn{2}{|l|}{$75.6 \%$} & \multicolumn{3}{|c|}{$22.2 \%$} & $2.2 \%$ & \multicolumn{2}{|l|}{$86.7 \%$} & \multicolumn{3}{|c|}{$8.9 \%$} & $4.4 \%$ \\
\hline $\mathbf{B 1 2}$ & $93.3 \%$ & & 4. & & & $2.2 \%$ & $88.9 \%$ & & 11. & & & $0 \%$ \\
\hline B13 & $97.8 \%$ & & & & & $2.2 \%$ & $95.6 \%$ & & 4.4 & & & $0 \%$ \\
\hline B16 & $57.8 \%$ & & 20. & & & $22.2 \%$ & $51.1 \%$ & & 20. & & & $28.9 \%$ \\
\hline B18 & $86.7 \%$ & & 8.5 & & & $4.4 \%$ & $93.3 \%$ & & 4.4 & & & $2.2 \%$ \\
\hline QUESTION & & PRE-TR & AIN & NG & ALUI & & & POST- & RAIS & ING & TALUE & \\
\hline & $\begin{array}{c}\text { NO } \\
\text { IMP. }\end{array}$ & $\begin{array}{r}\text { SOI } \\
\text { IM }\end{array}$ & $\begin{array}{l}\text { ME } \\
P .\end{array}$ & & $\begin{array}{l}\text { AT } \\
\text { P. }\end{array}$ & $\begin{array}{l}\text { VERY } \\
\text { IMP. }\end{array}$ & $\begin{array}{l}\text { NO } \\
\text { IMP. }\end{array}$ & & $\begin{array}{l}\mathrm{ME} \\
\text { IP. }\end{array}$ & & $\begin{array}{l}\text { EAT } \\
\text { IP. }\end{array}$ & $\begin{array}{l}\text { VERY } \\
\text { IMP. }\end{array}$ \\
\hline D2 & $0 \%$ & 20 & & & & $44.4 \%$ & $0 \%$ & & $6 \%$ & & $8 \%$ & $46.7 \%$ \\
\hline D3 & $2.2 \%$ & 11. & & & & $48.9 \%$ & $6.7 \%$ & & $2 \%$ & & $2 \%$ & $48.9 \%$ \\
\hline QUESTION & & PRE-TR & AIN & NG & LUE & & & POST- & RAIN & ING & TALUE & \\
\hline & & & LEM & INT & & & & & LEM & INT & & \\
\hline . & 1 & 2 & & & 4 & 5 & 1 & 2 & 3 & & 4 & 5 \\
\hline E2 & $64.4 \%$ & $68.9 \%$ & & & $20 \%$ & $4.4 \%$ & $80 \%$ & $80 \%$ & 28. & & $22.2 \%$ & $13.3 \%$ \\
\hline E3 & $6.7 \%$ & $77.8 \%$ & & & $4.4 \%$ & $0 \%$ & $6.7 \%$ & $91.1 \%$ & 15 . & & $2.2 \%$ & $2.2 \%$ \\
\hline
\end{tabular}

TABLE 5: The change in attitude towards Metacognitive Concepts (AM)

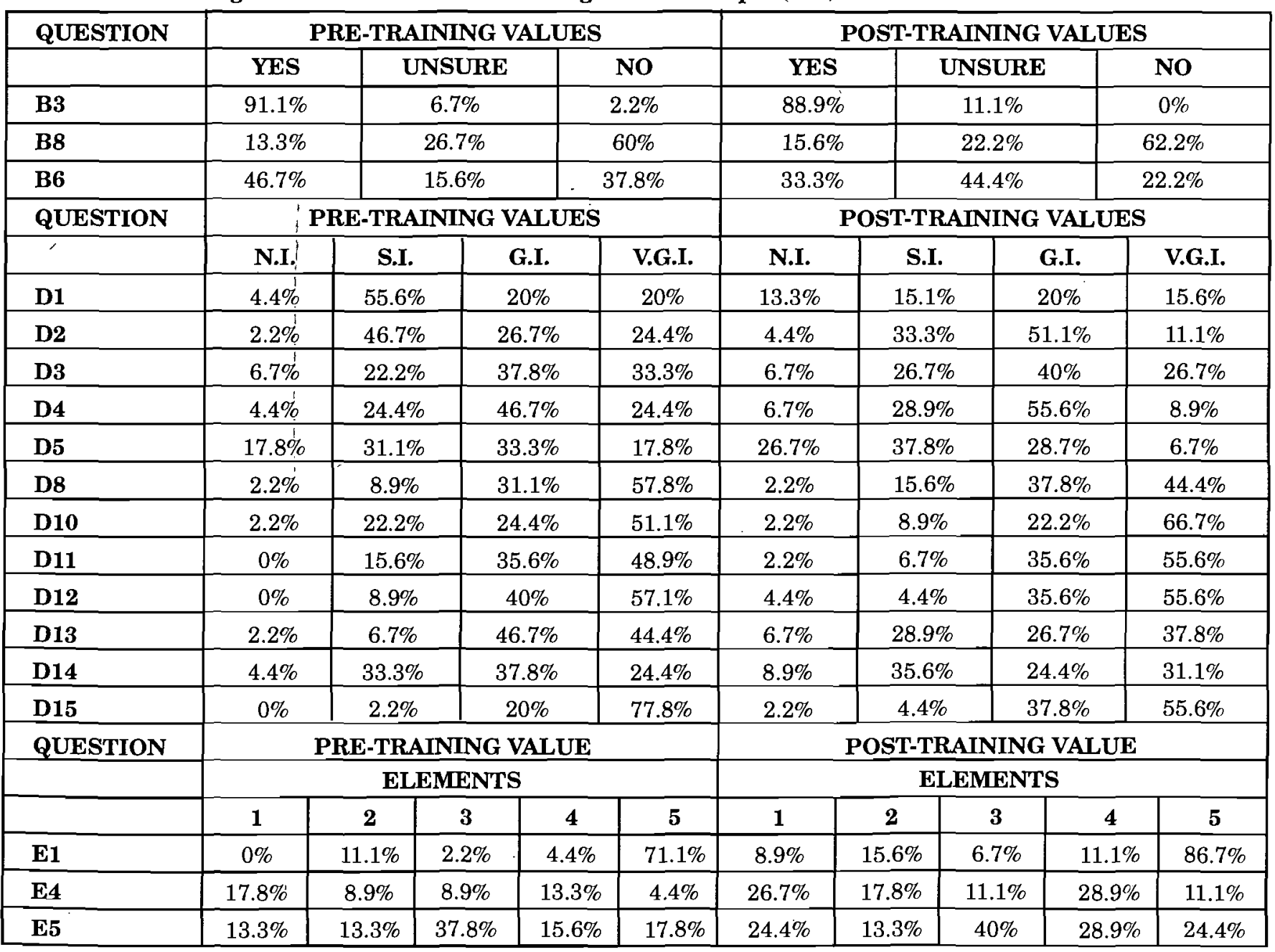


Table 5 and Figure 6) category showed a non-significant negative trend, indicating that the teachers' and therapists' attitude to metacognitive concepts was either poorer or more confused.

Examination of the overall means in the Attitude Neuropsychology category and of individual questions on the questionnaire indicated that the teachers and therapists believed in the potentially significant implications of the brain being involved in all aspects of the learning process. Metacognition, however, as the means for the Attitude Metacognition category were low (as before). There was also an even spread of frequencies in the individual questions, indicating either a lack of understanding of the concept of metacognition, or just reflecting the entrenched belief that teachers and therapists transmit prescribed content, control the way students receive and use it, and then test if they have received it (Knowles, 1990). This tends to reduce learning to simple incremental internalisation as opposed to creative reconceptualisation, which can only really be facilitated by geodesic approaches. From the increase in the number of neutral "unsure" and "of some importance" responses in this category, it appears that even after training the teachers and therapists were confused or uncertain as to the significance of metacognition.

Furthermore, analysis of the responses the definitions for both neuropsychology as well as metacognition, reveals a lack of understanding of the implications of geodesic approaches to learning, which is either a reflection of entrenched beliefs, or is the result of inadequate training regarding this concept. In order to explain why this result occurred, attitude as an entity needs to be examined.

According to Byron (1986: 142), attitude can be defined as "relatively lasting clusters of feelings, beliefs and behaviour tendencies directed toward specific persons, ideas, objects or groups". Attitudes are assumed to comprise three basic parts: an affective component (feeling), a cognitive component (belief), and a behavioural or intentional component ( Knowles, 1990).

From the spread in the results and the significant positive trend in the Attitude Neuropsychology category, it would seem that the affective and cognitive components were influenced by the training, and to a certain extent, the behavioural or intentional component, which is needed to complete the cycle of change. However, in the Attitude Metacognition category, the spread was not even and the change was not significant, indicating that there was an imbalance between attitudes towards metacognitive concepts and attitudes towards neuropsychological concepts. It therefore appears that the teachers and therapists understood the need to change to more neuropsychological approaches, but did not fully comprehend the importance of the metacognitive non-conscious level in the learning process, which confirms their traditional cognitive conscious sequential approach to learning. In order to change to a completely new system of learning as in the MMA, the attitude to both neuropsychological and metacognitive concepts needs to change in a balanced way. In order to convince individuals to change their attitude, the affective, cognitive and behavioural components of attitude would need to change more or less equally, not in the imbalanced way as occurred in Leaf's study (1997). Furthermore a balanced attitude change will only occur when feelings towards new concepts presented are positive, and not negative (Leaf, 1997: Byron, 1986). This has a significant implication for the speech-language therapist in a collaborative-consultative role in that attitude should be the priority of interaction before the provision of knowledge and skills.

Therefore, the results of the study by Leaf (1997) indicate that it is easier to change the attitude of teachers and therapists towards neuropsychological concepts because the 


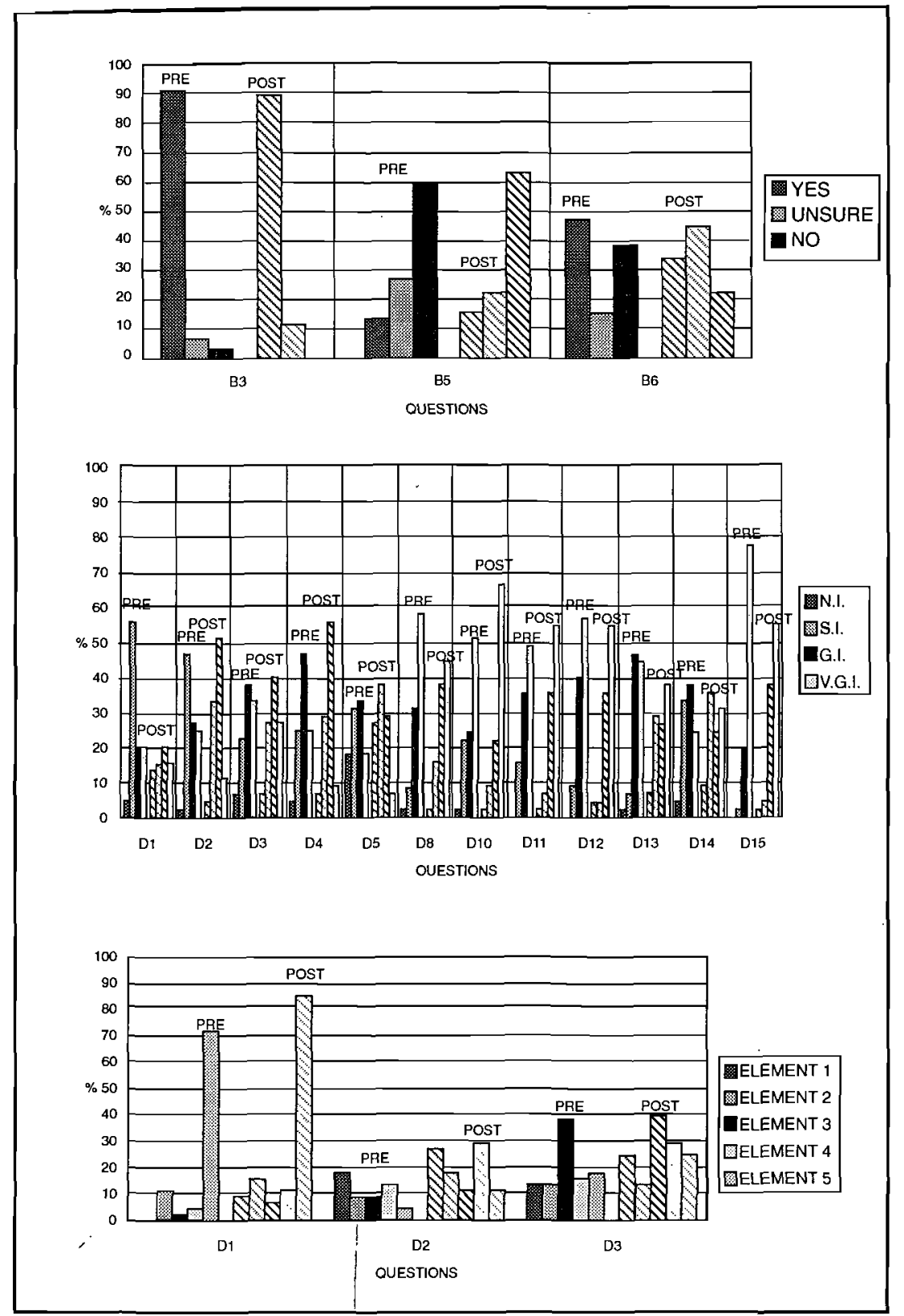

FIGURE 6. The Change in attitude towards Metacognitive Concepts skills are a necessary part of this change. However, it appears from the results of this study that the teachers and therapists were not convinced about a complete change in the system. This is possibly because traditional systems have been in place for so long and appear to be working. Alternatively, the teachers and therapists do not understand the implications of the change. It is postulated that this is one of the reasons that the teachers and therapists in this study are selecting only isolated components of the MMA in a disjointed fashion. According to the law of paradigms, however, past success guarantees nothing; in fact past so-called successful philosophies can block future vision (Barker, 1987). As Dewey indicated in 1896 (in Knowles, 1990), humans are in a constant state of change or flux, thus a static unchanging system, such as the current traditional educational system, will block human development. Knowles (1990) argues that perceptive observers of modern civilisation have long been asserting that the nineteenth century model of education is no longer functional in a world of accelerating change. He indicates that "contemporary educational enterprise is frozen into the nineteenth century model of education" (Knowles, 1990: 167). This unwillingness to change could also be the result of the elusiveness of the concept of learning, making a measurable, quantifiable and controllable system, as is the product of traditional behaviouristic and cognitive mechanistic theories, attractive. Alternative geodesic approaches, by contrast, may appear "uncontrollable", as they propose methodologies that are process oriented as opposed to product orientated. For instance, geodesic approaches propound co-operative learning (Johnson, Johnson \& Holubec, 1986 in Leaf, 1997), where the teacher plays a facilitative background role, as opposed to an authoritative expert foreground role. The

ideas invoked are logical and relate to the current philosophy propounded in many magazine articles and books, that consideration of brain research is imperative in education. However, consideration of the metacognitive non-conscious has many non-traditional implications, such as that the "teacher tell - pupil listen" paradigm is incorrect. This idea does not "fit" into the traditional mode of thought regarding teaching and learning, and is therefore more difficult to accept and implement. The implication is therefore to find ways of changing the three components of attitude of teachers and therapists to both neuropsychological and metacognitive concepts in a balanced way in order to effect total system changes. This could be done through providing more information on the differences between traditional and non-traditional learning systems emphasising the advantages of the latter and the disadvantages of the former.

In summary, it appears that the teachers and therapists agreed that changes in traditional systems are needed, and that neuropsychological approaches incorporating thinking speech-language therapist can play a major role in facilitating the change in teachers from providers of information to directors of learning.

From the results of the study (Leaf, 1997), the following attitudes to learning still persisted after training in the majority of the teachers and need therefore to be the focus of attention:

- Learning is controlled by the teacher or therapist (as opposed to being facilitated by the teacher and/or therapist, who requires the ability to convey respect, caring and support; provide data and feedback nonthreateningly; ask probing questions while keeping the locus of responsibility in the pupil; use the pupil as a source for his own learning; and listen empathetically).

- The learning environment is controlled and disciplined (as opposed to fostering a healthy scepticism toward authority, a spirit of inquiry and intellectual curiosity being fostered).

- Students learn from texts and from the teacher or 
therapist (as opposed to having a knowledge of the resources available and how to use these resources, e.g., how to identify data available in printed materials using the table of contents, the index and so on; how to scan quickly).

- Learning is the acquisition of isolated shills and techniques by drill, and therefore students need to listen uncritically, retain information, and predict exam questions (as opposed to having the ability to solve problems, formulate questions answerable by data, analyse data to produce answers to questions, and test data against criteria of reliability and validity).

- A competitive relationship with other pupils promotes learning (as opposed to a co-operative relationship between pupils promoting learning).

- Learning is a means to an end such as an exam (as opposed to its being a lifelong skill).

- The learning environment needs to be quiet and serious (as opposed to its being fun, exciting, stimulating and nonthreatening, that is, an environment of freedom within a structure).

- Logical and ordered teaching is important to the learning process (as opposed to multidimensional and collaborative teaching, which allows freedom of association, again within a structure).

- Laughing, playing and joking serve as breaks from the tedium of learning (as opposed to their being part of the whole learning process).

An additional interesting result of the study (Leaf, 1997), was that 65,7\% of the teachers were found to be reactive as opposed to proactive with regard to the facilitation of the learning process. Traditional philosophies of learning "condition the student to respond to the teacher's and therapist's stimuli; the initiative in the transaction is almost wholly in the teacher and therapist; the role of the student is to react" (Knowles, 1990: 209). This keeps the learner in a dependent role, limiting the learning to the paradigms set by the teacher. This study therefore lends support to the claim made by Iran-Nejad (1990) that traditional attitudes to learning limit the role of learning to the simple incremental internalisation of facts in a rote-learning fashion, and that this in turn fosters the achievement and motivational problems that children experience in schools. From this result, it becomes imperative that the speech-language therapist - acting within a consultative-collaborative role focuses on helping the teacher to view the learner as independent.

\section{THE CHANGE IN SKILLS}

Finally, the application of alternative geodesic approaches requires different types of skills and consequently roles from the teacher and therapist. This can be threatening as well as challenging for teachers and
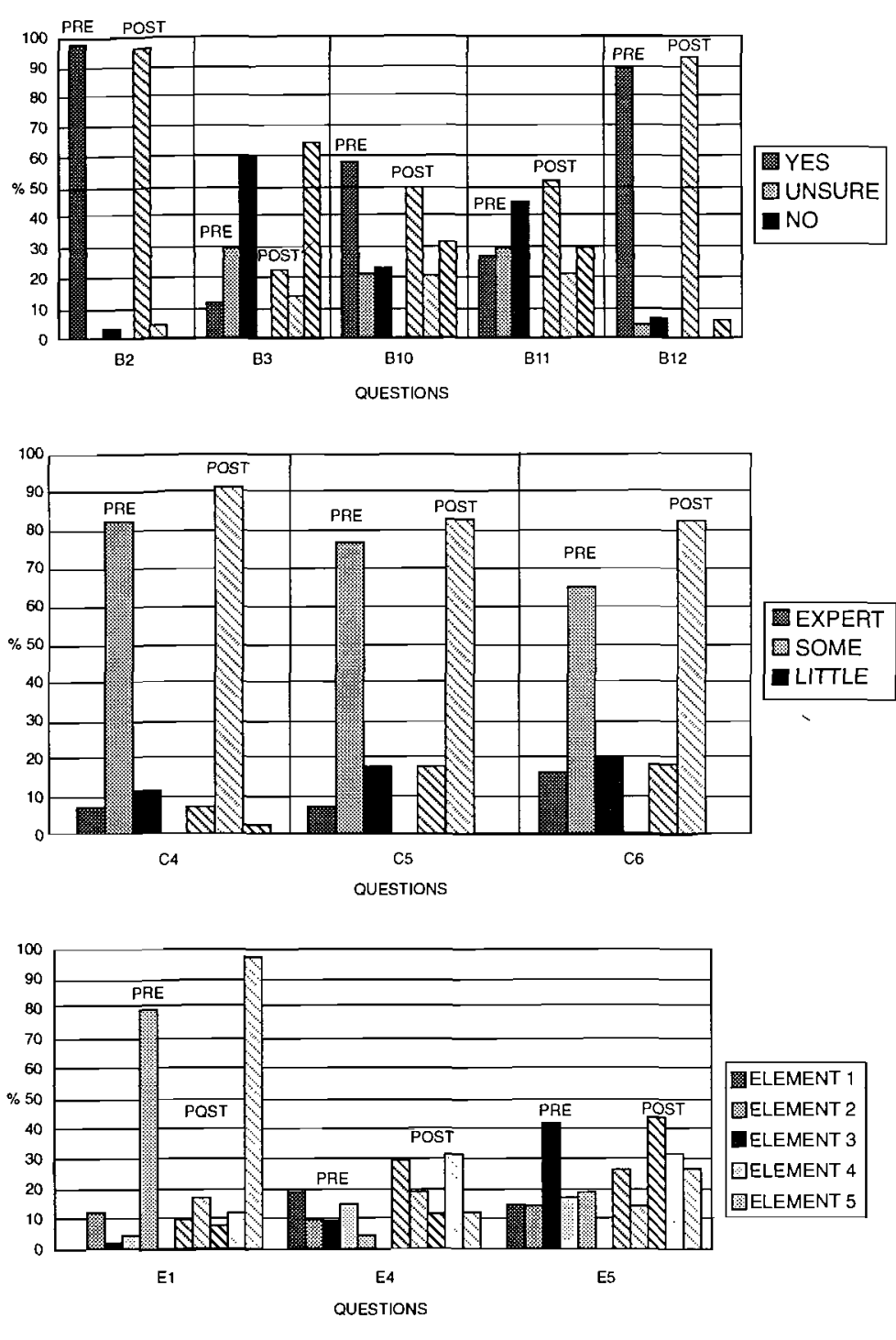

FIGURE 7: The Change in Neuropsychological Skills (SN) and Metacognitive Skills (SM)

therapists, who find it easier, therefore, to revert to "comfort zone" levels of skill. The skill level of change is examined in the next sub-section.

As indicated in the results, scores in both the Skills in applying neuropsychological concepts and the skills in applying metacognitive concepts showed significant improvement after training (see Table 6 and Figure 7). However, examination of the means of the scores before and after training for both categories indicates that although there was an improvement in teachers' and therapists' skills, the skill levels were initially low. These results appear to indicate that traditional beliefs or paradigms are so entrenched or conditioned that even though the teachers or therapists are aware that a complete change to more geodesic approaches to learning is needed, they automatically revert to what they know, or are comfortable with. Alternatively, their conditioning or paradigms could be blocking their ability to understand and therefore apply more wholistic methods and consequently, they do not actually know what to do. Thus, their intentional, behavioural and actual skill application level of geodesic principles is low. These results confirm Knowles' 
(1990) postulation that contemporary educational enterprise is seemingly frozen into an outdated nineteenth century model.

Furthermore, even though change occurred during the post-training phase, traditional teaching and therapy methods were still being used, with only elements of the MMA methods being applied, which would account for the low means obtained for the skills levels. However, some improvement did occur, which indicates that benefit was derived by the teacher's and therapist's from the MMA training regarding skills.

With regards to the teacher's skills, (see Table 6 and Figure 7), it appeared that the majority of the teachers were using Metacognitive-Mapping predominantly with cultural subjects and English, with very few using it with Afrikaans or Maths. Moreover, from the comments on the questionnaires, it appeared that the teachers were using Metacognitive-Mapping as a summary at the end of a lesson after "teaching" in the traditional format. Thus the Metacognitive-Mapping Approach was utilised as a supplementary aid and a way of summarising, not as a total system. The teachers and therapists did not use the co-operative teaching concept along with the Metacognitive-Map, which is part of the presentation of information. It appears that they viewed the Metacognitive-Map as a way of reinforcing the memorisation of facts, and of "getting the information into the pupils' heads for future reproduction", in other words, as a means to an end. The MMA was thus not viewed as a way of facilitating thinking and the creative expansion of thought, as a process of development. It is almost as if the geodesic methods of the MMA were changed into traditional "tools", and thus viewed as something "extra to do", and not as an alternative approach to turn the product of education into a lifelong learning experience. For instance, music, which should be played throughout the lessons in order to facilitate concentration and increase the rate of learning, was used intermittently to relax the children, and only by $60 \%$ of the teachers and therapists; secondly, the relaxation exercises, which should be used at least daily to release the correct chemicals to facilitate the metacognitive and cognitive processes, were used sporadically by only $20 \%$ of the teachers; and, thirdly, the Metacognitive-map, which should be used continuously in exchanging information, solving problems, creating, memorising, organising thinking and information, and facilitating inquiry-directed research, was only really used as a summary "tool", and study method.

Furthermore, difficulty was experienced with the following skill applications of the MMA methods:

- Getting students to read faster using a pacer in order to improve comprehension

- Stopping students re-reading within a sentence, which reduces comprehension

- Using Metacognitive-mapping all the time, that is for planning lessons, presenting lesson content, discussions, studying - in other words, wherever there is an exchange of information

- Improving comprehension through the "jig-saw puzzle" method of the MMA, which applies an organised inductive and deductive approach to a text culminating in a Metacognitive-map as opposed to reading and rereading through work, underlining key words and making linear notes

- Differentiating between key words and key concepts, and facilitating this understanding in children

- Becoming a facilitator as opposed to a teacher, that is, moving away from the "teacher tell - pupil listen" paradigm

- Using co-operative teaching techniques

- Teaching pupils how to make Metacognitive-maps independently as well as assisting pupils in the use of the MMA as a study technique.

Few teachers or therapists used the MMA geodesic methods as an entire global cycle. Most of the teachers only

TABLE 6: The change in Neuropsychological Skills (SN) and Metacognitive Skills (SM)

\begin{tabular}{|c|c|c|c|c|c|c|c|c|c|c|}
\hline QUESTION & \multicolumn{5}{|c|}{ PRE-TRAINING VALUES } & \multicolumn{5}{|c|}{ POST-TRAINING VALUES } \\
\hline & \multicolumn{2}{|l|}{ YES } & \multicolumn{2}{|l|}{ UNSURE } & NO & \multicolumn{2}{|c|}{ YES } & \multicolumn{2}{|c|}{ UNSURE } & NO \\
\hline B13 & \multicolumn{2}{|l|}{$79.8 \%$} & \multicolumn{2}{|l|}{$0 \%$} & $2.2 \%$ & \multicolumn{2}{|c|}{$95.6 \%$} & \multicolumn{2}{|l|}{$4.4 \%$} & $0 \%$ \\
\hline B14 & \multicolumn{2}{|l|}{$11.1 \%$} & \multicolumn{2}{|l|}{$28.9 \%$} & $60 \%$ & \multicolumn{2}{|c|}{$22.2 \%$} & \multicolumn{2}{|l|}{$13.3 \%$} & $\% 64.4$ \\
\hline B15 & \multicolumn{2}{|l|}{$57.8 \%$} & \multicolumn{2}{|l|}{$20 \%$} & $22.2 \%$ & \multicolumn{2}{|c|}{$48.9 \%$} & \multicolumn{2}{|l|}{$\%$} & $31.1 \%$ \\
\hline B16 & \multicolumn{2}{|l|}{$26.7 \%$} & \multicolumn{2}{|l|}{$28.9 \%$} & $44.4 \%$ & \multicolumn{2}{|c|}{$51.1 \%$} & \multicolumn{2}{|l|}{$20 \%$} & $28.9 \%$ \\
\hline B17 & \multicolumn{2}{|l|}{$88.9 \%$} & $4.4 \%$ & \multicolumn{2}{|c|}{$6.7 \%$} & & & $0 \%$ & & $.7 \%$ \\
\hline QUESTION & & PRE-TR & AINING & LUES & & & POST- & RAINING & ALUES & \\
\hline & EXPER & & SOME & & TLE & EXI & & SOME & & TTLE \\
\hline C4 & $6.7 \%$ & & $82.2 \%$ & & $1 \%$ & & & $91.1 \%$ & & $.2 \%$ \\
\hline C5 & $6.7 \%$ & & $75.6 \%$ & & $8 \%$ & & & $82.2 \%$ & & $0 \%$ \\
\hline C6 & $15.6 \%$ & & $64.4 \%$ & & $0 \%$ & & & $82.2 \%$ & & $0 \%$ \\
\hline QUESTION & & PRE-TR & AINING & LUES & & & POST & RAINING & ALUES & \\
\hline & & & ELEMEN & & & & & ELEMEN & & \\
\hline & 1 & $\mathbf{2}$ & $\mathbf{3}$ & 4 & $\mathbf{5}$ & 1 & 2 & 3 & 4 & $\mathbf{5}$ \\
\hline E1 & $0 \%$ & $11.1 \%$ & $2.2 \%$ & $4.4 \%$ & $71.1 \%$ & $8.9 \%$ & $15.6 \%$ & $6.7 \%$ & $11.1 \%$ & $86.7 \%$ \\
\hline E4 & $17.8 \%$ & $8.9 \%$ & $8.9 \%$ & $13.3 \%$ & $4.4 \%$ & $26.7 \%$ & $17.8 \%$ & $11.1 \%$ & $28.9 \%$ & $11.1 \%$ \\
\hline E5 & $13.3 \%$ & $13.3 \%$ & $37.8 \%$ & $15.6 \%$ & $17.8 \%$ & $24.4 \%$ & $13.3 \%$ & $40 \%$ & $28.9 \%$ & $24.4 \%$ \\
\hline
\end{tabular}


adopted isolated components in a disjointed fashion. It appears that teachers and therapists did not know how to use the various procedures, and therefore selected those that they were comfortable with. Furthermore, the resistance to change by the therapists and teachers appears to be the result of being set in traditional paradigms.

\section{GENERAL CONCLUSION REGARDING THE CHANGE IN TEACHERS' AND THERAPISTS' KNOWLEDGE, ATTITUDE AND SKILLS}

Although the overall results of the research by Leaf (1997) indicate that a significant change did occur in the teachers' and therapists' knowledge, attitude and skills regarding the geodesic principles of the MMA, it is postulated that these changes were not sufficient to produce an attitude of complete change in the teachers that would be long-lasting. Thus, in the post-training phase the teachers and therapists were not applying the MMA geodesic methodology as an entire global cycle, they were adopting isolated components in a disjointed fashion. The results also indicated a persistence of traditional beliefs or paradigms regarding the learning process in the majority of the teachers and therapists. The speculation arises that this resistance to change is based on attitude, and that unless all three components of attitude (affective, cognitive, behavioural) are changed in a balanced way, long-lasting global changes will not be effected. Therefore, it appears to be relatively easy to increase a person's knowledge and to improve a person's skill under supervision. However, unless there is a total change in all the components of attitude, this knowledge will not be utilised, and the skill levels regarding the use of the MMA will not increase sufficiently to allow effective autonomous and long-lasting application.

These findings support the literature dealing with the importance of attitude change (Byron, 1986). This has important implications for the speech-language therapist in a consultative-collaborative role in that geodesic training needs to incorporate techniques that will facilitate a change in attitude towards alternative forms of education, and will therefore overcome existing traditional paradigms. Furthermore, learning methodology has to have more of an emic perspective (Leaf, 1997; Leaf et al., 1997). The "teacher tell - pupil listen" paradigm that becomes prominent in the higher standards does not allow for analytical, evaluative or creative thinking or for the application of knowledge in problem-solving . In addition "the content-overload of most syllabi prevents even the most skilled teacher from using time to develop pupils' active thinking rather than just memorisation in order to accrue marks" (Adams \& Wallace, 1991: 105). This study underscores the seriousness of the situation in that incorrect facilitation of learning will actually inhibit the development of potential. It is thus imperative to provide a consultative-collaborative service to teachers to correct this very real problem.

It is also felt that the speech-language therapist can play a consultative-collaborative role within schools for the learning disabled. Borkowski, Schneider and Pressley (1989), who conducted research on the challenges involved in teaching information processing to learning disabled pupils, found limited performance gains in pupils who received strategy instruction in information processing, and thinking and problem-solving skills. This was attributed to the fact that individual learning styles were not incorporated in the strategy training. Although the neurological deficiencies of the learning disabled pupil can undermine metacognitively-oriented training, and the special educator needs to confront realistically all the possible constraints, there is, however, considerable evidence from the current research, as well as from the literature, that it is possible to improve the learning potential of academically delayed as well as normal pupils. According to Scruggs and Brigham (1987) and Borkowski et al. (1989), wholistic education can do much to improve the functioning of pupils with learning disabilities and average achieving pupils by attempting to train information processing. It is proposed that the training of information processing can only occur within a geodesic system where students are allowed to explore at their own pace what their strengths and learning styles are, which is inhibited by the traditional system. There are countless "thinking skills" and metacognitive training programmes available (for example De Bono, 1991; Adams \& Wallace, 1991; Paris \& Winograd, 1990; Kaniel \& Reichenberg, 1990; Palmer et al., 1989; Derry, 1990) which all encourage the use of metacognitive strategy training to improve the performance of the learning disabled and normal population. All these programmes report exciting, but fairly conservative gains in potential. Analysis of the frameworks employed in the above programmes reveals an emphasis on behaviour modification and cognitive philosophies. Therefore, although wholistic skills were being trained by these programmes, they were being trained within traditional frameworks. As has been demonstrated in the current study, trying to incorporate geodesic methods into behaviouristic traditional philosophies does not work; it can in fact cause a lower performance in pupils. Entirely new systems have to be created that adopt the geodesic philosophy into which strategy training can fit, and it is believed that higher success rates will then be achieved.

There are some studies reported in the literature (Kaniels \& Feuerstein, 1989; Derry, 1990; Erskine 1986; de Capdevielle, 1986; Van der Vyver, 1985; Van der Vyver \& Capdevielle, 1990; Thembela, 1986; Schuster, 1983; Edwards, 1983; Dhority, 1984; Odendaal, 1986; Botha, 1985 in Leaf 1997) which employ a more holistic geodesic orientation, that are more in line with the philosophy of the research by Leaf (1997), and that provide promising results. These studies report greater success in students' process and product performance rates than in product performance alone. Currently in South Africa there is a project called the Upptrail trust that has been underway since the mid-eighties. Its inception was at the University of Stellenbosch, and it was designed to deal with the major problems inherent in black education. The Upptrail project is based on suggestopeadic philosophy, and employs a systems approach which suggests that there is a systematic relationship between social conditions and educational competence (Thembela, 1986).

The scientific monitoring of the Upptrail project, currently in progress, reveals that beneficial gains in terms of innovative lifeskill learning are being made. The current research falls in line with this research in that it promotes complete system changes that endeavour to place the benefits of knowledge and the development of potential at everyone's disposal. Once the positive results of such research, as well as of the current research, are demonstrated to education departments, the private sector and. institutions, wider implementation of similar in-service. programmes may táke place. 
In conclusion, it is speculated that, if the utilisation of isolated elements of geodesic approaches, as in the study by Leaf (1997), is able to produce a positive change in teachers, therapists and pupils, how much more of an effect will utilisation of the entire global spectrum of geodesic learning produce.

\section{CONCLUSION}

The argument of the current article is twofold: firstly, to emphasise the need to change the perception of the traditional view of learning as a "mosaic of educational and therapeutic programmes conducted by a plethora of largely unconnected institutions" (Knowles, 1990:171), into a lifelong learning resource system or learning community. This implies that learning should be viewed as an internal construction process controlled by the learner, as opposed to the internalisation of external facts from an external source such as a teacher; secondly, to discuss the changed role of the speech-language therapist from that of language instructor to that of a learning facilitator within a collaborative-consultative role.

This alternative approach can be accomplished via the restructuring of learning environments so that they reflect the dynamic and spontaneous learning approaches that worked for children before school, and that follow the natural laws of brain functioning. This would entail: the eradication of memorizing isolated materials for an end result such as an exam - a product, and replacing it by the facilitation of meaningful and useful knowledge extension and understanding of concepts and their interrelations - a learning process; creating authentic learning opportunities in real world contexts. Therefore, learning intentions within a geodesic framework are changed from optimizing the conditions for encoding and retrieval under otherregulation, to optimizing the conditions for understanding and personal growth under self-regulation (Iran-Nejad, 1990; Gardner, 1985; Knowles, 1990; Jensen, 1995).

Geodesic methodologies such as the MMA discussed in this article, and in depth in Leaf, 1997 and Leaf et al., 1997, are alternative systems as opposed to "methods" that can be componentially adopted $a$ id lib into a traditional system. It is postulated that the $a d \mid l i b$ componential adoption of geodesic methods will result in improved "side effects", as opposed to an improved thinking and processing system in an individual. It is proposed that this is what has happened in the study by Leaf (1977). Initially it was predicted that geodesic methodologies could be-adopted into traditional frameworks, and in this way, new systems could be created. However, the results of the study indicate otherwise. It would seem that the new system has first to be created and adopted by the teachers and therapists. Then, once the philosophy and methods of the new system have become implicit or conditioned, the positive aspects of the traditional system could be reintroduced in a componential fashion. In this way, the positive aspects of traditional systems could be utilised and the damaging negative aspects discarded.

The article also discusses the current educational and therapy needs for transforming traditional approaches to education and therapy in South Africa which are in a process of review. The results of the study by Leaf (1997) show that this change can be facilitated by using the geodesic approach which will be discussed further under clinical applications.

It has become evident that "merely increasing financial resources on a system which is incapable of providing human society with the enhanced human capabilities necessary to operate and contribute to a better society can be counterproductive" (LTFA, 1995). In 1974 a World Bank report concluded that the two previous decades of formal traditional educational systems had proved irrelevant to the needs of developing countries, as they tended to kill entrepreneurial and community interests (LTFA, 1996). Clearly new systems are needed to resolve the situation. A new system is a broad view which transcends technological problems and demands, and implies a basic reorientation in scientific thinking (Knowles, 1990), in other words, systems theory (Von Bertalanaffy, 1968). It is into the systems theory that the geodesic approach fits as systems theory is not a theory in the usual scientific sense of a discrete system of assumptions, constructs, and functional relationships which explains and predicts the behaviour of some particular phenomena. Systems theory is a set of principles, an orientation in thinking, a general body of knowledge applicable in a wide variety of circumstances" (Knowles, 1990). It applies in situations where "wholeness" is important, and this is usually the case when dealing with problems of education and learning (Hayman, 1975: 3).

The uniqueness of the MMA geodesic approach is specifically that it offers a unified theoretical account, as well as a practical model, of a number of geodesic psychological phenomena that are discussed and evaluated in the literature, but have heretofore been unrelated into a unified theory and practical application. That is, the elements or procedures of the MMA are examples of what many teachers and therapists would recognize as basic as well as desirable tenets of a wholistic learning environment, and which have been used in isolation in learning environments before. The uniqueness of the MMA is the degree to which these components are integrated into a practical framework functional within daily therapist/ teacher/pupil interactions. Therefore, the geodesic approach of the MMA not only provides a set of principles and an orientation in thinking, but also a practical framework enlisting geodesic philosophy and systems theory to be operationalised.

\section{REFERENCES}

Adams, H.B. \& Wallace, B. (1991). A Model for Curriculum Development: TASC in Gifted Education International, 7, 194213.

Anderson, J.R. (1985). Cognitive Psychology and its Complications (2nd ed). New York: W.H. Freeman.

Barker, J.A. (1987). Discovering the Future: A Question of Paradigms. Charterhouse Productions: S.A. Breweries.

Borkowski, J., G., Schneider, W. \& Pressley, M. (1989). The Challenges of Teaching Good Information Processing to the Learning Disabled Student. International Journal of Disability, Development and Education, 3 (3), 169-185.

Botkin, J.W., Elmandjra, M. \& Malitza, M. (1979). No Limits to Learning. Bridging the Human Gap: A Report of the Club of Rome. Oxford and New York: Pergammon Press.

Brown, A.L. (1978). Knowing When, Where and How to Remember: A Problem of Meta-cognition in Glaser, R. (Ed.). Advances in Instructional Psychology. Hillsdale, N.J: Erlbourne.

Buzan, T. (1991). Use Both Sides of Your Brain. New York: Plume. Buzan, T. \& Dixon, T. (1976). The Evolving Brain. Exetar: Wheaten \& Co, Ltd.

Byron, R. (1986). Behaviour in Organisations: Understanding and Managing the Human Side of Work. (2nd ed.) Boston, Mass.: Allyn and Bacon.

Campbell, B., Campbell, L. \& Dickinson, D. (1992). Teaching and Learning through Multiple Intelligences. Seattle, Washington: New Horizons for Learning. 
Capra, F. (1982). The Turning Point: A New Vision of Reality in The Futurist, 16 (6), 19-24.

Damico, J.S. (1987). Addressing Language Concerns in the Schools: The SLP as Consultant. Journal of Childhood Communication Disorders, 11 (1), 17-40

de Capdevielle, B. (1986). An Overview of Project Intelligence. Per Linguam, 2 (2), 31-38.

Derry, S.J. (1990). Remediating Academic Difficulties through Strategy Training: The Acquisition of Useful Knowledge in Remedial and Special Education, 11 (6), 19-31.

Faure, C. (1972). Learning to Be: The World of Education Today and Tomorrow. Paris: UNESCO.

Gardner, H. (1985). Frames of Mind. New York: Basic Books

Gerber, A. (1987). Collaboration between SLP's and Educators: A Continuity Education Process. Journal of Childhood Communication Disorders, 11 (1-2), 107-125.

Glasser, M.D. (1986). Control Theory in the Classroom. New York: Harper \& Row.

Gould, S. (1973). Commission on Nontraditional Study. Diversity by Design. San Francisco Jossey-Bass.

Gould, S. (1981). The Mismeasure of Man. New York: W.W. Norton.

Hayman, J.L. (1975). Systems Theory and Human Organization in Zalatimo, Sulerman, D. \& Sterman, P.J. (Eds). A Systems Approach to Learning Environments. Roselle, N.J.: MEDED Projects, Inc.

Iran-Nejad, A. (1990). Active and Dynamic Self-Regulation of Learning Processes. Review of Educational Research, 60 (4), 573-602.

Jensen, E. (1995). Brain-Based Learning and Teaching. South Africa : Process Graphix

Johnson, J.M. (1987). A Case History of Professional Evolution, From SLP to Communication Instructor. Journal of Childhood Communication Disorders, 11 (4), 225-234.

Kaniels, S. \& Feuerstein, R. (1989). Special Needs of children with Learning difficulties. Oxford Review of Education, 15 (2), 165-179.

Knowles, M. (1990). The Adult Learner: A Neglected Species. Houston: Gulf Publishing Company.

Kline, P. (1990). Everyday Genius. Arlington, V.A.: Great Ocean Publishers.
L.T.F.A. (1995). Unpublished Lecture Series on "Brain-Based Learning". South Africa: Lead the Field Africa.

Lazar, C. (1994). A Review / and Appraisal of Current Information on Speech / Language Alternative Service Delivery Models in Schools. Communiphon, 308, 8-11.

Leaf, C.M., (1990). Mind-Mapping: A Therapeutic Technique for Closed Head Injury. Unpublished Masters Dissertation, University of Pretoria.

Leaf, C.M. (1997). The Mind-Mapping Approach: A Model and Framework for Geodesic Learning. Unpublished D.Phil Dissertation, University of Pretoria.

Leaf, C.M., Uys, I.C. \& Louw, B., (1993). Mind Mapping: A Culture and Language 'free' technique. South African Journal of Communication Disorders, 40, 35-43.

Novak, J.D. \& Gowin, B. (1984). Learning how to Learn. Cambridge: Cambridge University Press.

Okebukola, P.A., (1992). Attitudes of Teachers Towards Concept Mapping and Vee-diagramming as Metalearning Tools in Science and Mathematics. Educational Research, 34 (3), 201212.

Palmer, L.L., Alexander, M. \& Ellis, N. (1989). Elementary School Achievement Results following In-Service Training of an Entire School Staff in Accelerative Learning and Teaching: An Interim Report. Journal of the Society for Accelerative Learning and Teaching, 14 (1), 55-79.

Paris, S.G. \& Winograd, P. (1990). Promoting Metacognition and Motivation of Exceptional Children. Remedial and Special Education, 11 (6), 7 - 15.

Paul-Brown, D. (1992). Professional Practices Perspective on Alternative Service Delivery Models. ASHA Bulletin, 12.

Scruggs, E. \& Brigham, J. (1987). The Challenges of Metacognitive Instruction. RASE, 11 (6), 16-18.

Simon, C.S. (1987). Out of the Boom Closet and into the Classroom: The Emerging SLP. Journal of Childhood Communication Disorders, 11 (1-2), 81-90.

Tattershall, S. (1987). Mission Impossible: Learning How a Classroom Works Before its Too Late!. Journal of Childhoold Communication Disorders, 11 (1), pp. 181-184.

Thembela, A. (1990). Education for Blacks in South Africa: Issues, Problems and Perspectives. Journal of the Society for Accelerative Learning and Teaching, 15 (1\&2), 45-57. 